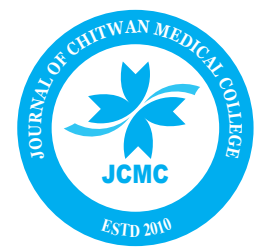

\author{
Journal of Chitwan Medical College 2020;10(33):8-11 \\ Available online at: www.jcmc.com.np
}

\title{
STRESS AND ANXIETY AMONG NURSES WORKING IN TERTIARY CARE HOSPITALS IN NEPAL DURING COVID- 19 PANDEMIC
}

Mamata Sharma Neupane', Siddeshwar Angadi', Alisha Joshi ${ }^{1,{ }^{*},}$, Harish Chandra Neupane ${ }^{2}$

${ }^{1}$ School of Nursing, Chitwan Medical College, Bharatpur-10, Chitwan, Nepal

${ }^{2}$ Department of Surgery, Chitwan Medical College, Chitwan, Nepal

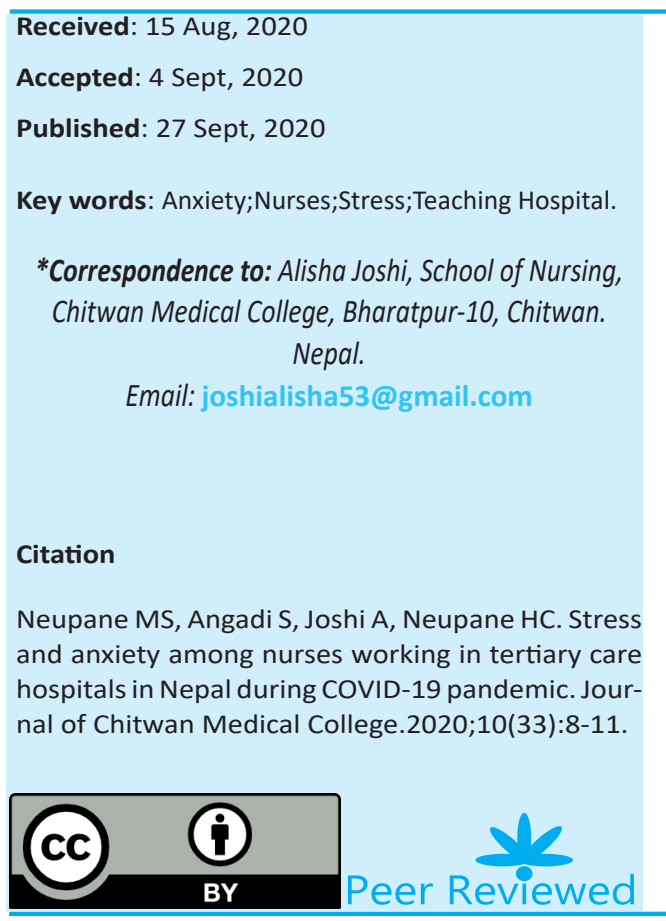

INTRODUCTION

Corona Virus Disease 2019 (COVID-19) is an infectious disease which was first discovered in December 2019 in Wuhan, China, and has spread globally, resulting in an ongoing pandemic ${ }^{1}$ COVID-19 pandemic has hit around total of 213 countries with 1,24,01262 confirmed cases and 559047 death worldwide, whereas in Nepal the number is growing gradually and have reached 16801 confirmed cases as of July 12, 2020 with 38 deaths and 8589 recovered. ${ }^{2}$

The high prevalence of COVID-19 in many countries, its novelty and highly infectious nature has placed an unprecedented demand on health system globally and the worst effect observed in already fragile healthcare system in developing nations like Nepal. High stress roles with unique demands, the fear of contagion, stigmatization, social isolation and compulsion of performing duty have undeniably brought extreme stress and anxiety in healthcare workers. ${ }^{4,5}$ Evidences reported that the health workers directly involved in the diagnosis, treatment, and care of patients with COVID-19 are at risk of developing mental health symptoms. ${ }^{6-12}$ In addition, The International Council of Nurses (ICN) highlighted the increased anxiety and stress for nursing staff during this crisis in countries around the world ${ }^{5}$ In this context, addressing and understanding stress and anxiety among the nurses is the critical part to prevent various mental problems. Hence, this study aimed at assessing stress and anxiety among nurses to depict the prior picture in controlling the stress and anxiety in an attempt to ensure positive mental well-being and promote satisfaction and standardization in patient care

\section{METHODS}

Descriptive cross-sectional survey was used to assess the stress and anxiety among nurses working in Teaching Hospitals, Bharatpur. A total of 181 nurses form Emergency wards, critical care unit and general wards of Chitwan Medical College and Teaching Hospital (CMCTH) were the population of our study. Among them all the 181 nurses were eligible and were taken as a study sample using non probability consecutive sampling technique with the administrative approval.

Question related to stress developed by Cohen et al. $(1988)^{13}$ was used to assess the stress of the nurses and analysis was done as: Low stress-0-13, Moderate stress-14-26 and High stress- 27-40 and Question related to anxiety developed by William W. K. Zung M.D, (1929-1992) ${ }^{14}$ was used to assess 
anxiety of nurses and analysis was done as: Normal 20-44, Mild to moderate $-45-59$, Intense to severe-60-74 and Extreme- $\geq 75$.

Prior to data collection, ethical approval was obtained from CMC- Institutional review Committee (IRC) Bharatpur, Chitwan. After that all participants were sent an email inviting them to participate in the study. The email outlined the purpose, the voluntary nature of participation and emphasized the anonymity of the study. This email also contained a web link to the online survey form. Online survey form was made accessible to the nurses from $26^{\text {th }}$ April 2020 to $5^{\text {th }}$ June 2020 and survey responses were collected online and only available to the researchers in a non-identifiable form by giving code number, not disclosing the information and using the information only for the research purpose. A total of 181 nurses from selected wards participated in the web-based survey. Collected data was exported into IBM SPSS (Statistical Package for Social Sciences) version 20 for window. Then data were analyzed in terms of descriptive statistics.

\section{RESULTS}

A total of 181 nurses working in various wards participated in the web based survey. Out of 181 nurses, most of them (83.4\%) were between age $20-24$ years, majority (74.6\%) had completed PCL nursing, nearly half (42.0\%) were working in critical care unit followed by $(41.4 \%$ ) from general ward. Majority $(68.0 \%)$ of the nurses had work experiences more than 1 year whereas, more than half (51.9\%) attended training on COVID-19 (Table 1)

Table 1: Respondents' demographic characteristics

$n=181$

\begin{tabular}{|l|c|}
\hline Variables & Frequency (\%) \\
\hline Age & $151(83.4)$ \\
\hline $20-24$ years & $30(16.6)$ \\
\hline More than 24 years & $135(74.6)$ \\
\hline Qualification & $19(10.5)$ \\
\hline PCL Nursing & $27(14.9)$ \\
\hline Bachelors in Nursing & \\
\hline BSc Nursing & $76(42.0)$ \\
\hline Area of Work & $75(41.4)$ \\
\hline Critical care unit & $30(16.6)$ \\
\hline General ward & \\
\hline Emergency unit & $36(19.9)$ \\
\hline Work experience & $22(12.1)$ \\
\hline More than 6 months & $123(68.0)$ \\
\hline 1 year & \\
\hline More than 1 year & $94(51.9)$ \\
\hline Training on Covid-19 & $87(48.1)$ \\
\hline Yes &
\end{tabular}

Regarding level of stress while working during COVID-19 pandemic, more than half $(54.7 \%)$ of the respondents experienced moderate level of stress, $37.6 \%$ of respondents experienced high level of stress while least (7.7\%) of respondents experienced low level of stress as shown (Table2)

Table 2: Respondents' level of stress

\begin{tabular}{|l|c|}
\hline Level of stress & Frequency (\%) \\
\hline High & $68(37.6)$ \\
\hline Moderate & $99(54.7)$ \\
\hline Low & $14(7.7)$ \\
\hline Total & $181(100)$ \\
\hline
\end{tabular}

On respondents' level of anxiety working during COVID-19 pandemic, finding shows that most (88.4\%) of the respondents were normal while $10.5 \%$ of respondents experienced mild to moderate level of anxiety and only $1.1 \%$ experienced severe level of anxiety as shown (Table3)

Table 3: Respondent's level of anxiety

\begin{tabular}{|l|c|}
\hline Level of Anxiety & Frequency (\%) \\
\hline Normal & $160(88.4)$ \\
\hline Mild to Moderate & $19(10.5)$ \\
\hline Intense to Severe & $2(1.1)$ \\
\hline Total & $181(100)$ \\
\hline
\end{tabular}

\section{DISCUSSION}

Corona virus disease 2019 (COVID-19) pandemic has a rapid acceleration leading to a burden on global health care systems worldwide leading to great psychological pressure on nurses treating the patients with COVID-19. Evidences have showed the rise in psychological problems including stress, anxiety, depression, post traumatic stress disorder worldwide among the health care workers. ${ }^{15-17}$ The stress and anxiety related to pandemics also influence the behavior of people especially among the health care members. ${ }^{18}$ There is much similarity like illness between swine flu, SARS and COVID-19 infection. Among the above illnesses are viral in origin involving the respiratory system and spreading by droplet infection. Unfortunately, there is no specific treatment or vaccine available for COVID-19 infection which further increases the intensity of stress and anxiety. ${ }^{19-21}$

In this study $37.6 \%$ of nurses experienced high level of stress whereas, $54.7 \%$ of nurses experienced moderate level of stress. The finding from Tam, C.W and colleague also reported a high level of stress among $68 \%$ of health care workers and about $57 \%$ were found to have experienced psychological distress. ${ }^{22}$ In addition, a study conducted in Toronto during the SARS outbreak revealed that less than $50 \%$ of staff experienced high degree of distress treating the patients influenced by factors like job stress, perceiving stigmatization, coping by avoiding crowds and colleagues, and feeling scrutinized. ${ }^{21}$ Further, Xinshen and colleague found high psychological pressure among ICU nurses in Wuhan with regards to huge workload, long-term fatigue, infection threat, and frustration with the death of patients whom they care, Additionally, they worried about their families and vice versa. ${ }^{23}$ Likewise, a study conducted in Taiwan among nurs- 
ing staffs revealed that Nearly two-thirds (61.8\%) of the participants earned psychological and emotional distress scores within the 'normal' range, and 3.4\% earned scores indicating severe distress ${ }^{24}$ Similarly, evidences from multi centre study from Singapore and India concluded that 20 (2.2\%) health workers experienced moderate to extremely-severe stress, whereas, 34 (3.8\%)moderate to severe levels of psychological distress. ${ }^{11}$

Our study revealed that $10.5 \%$ of nurses had mild to moderate level of anxiety which is consistent with the finding from study in china which revealed that prevalence of anxiety was $12.5 \%$, with mild $(10.35 \%)$, moderate $(1.36 \%)$ and severe anxiety $(0.78 \%) .{ }^{25} \mathrm{~A}$ meta-analysis on psychological impact of $\mathrm{CO}$ VID-19 on healthcare workers from 12 Asian studies reported 23.2\% prevalence of anxiety among health workers. ${ }^{26}$ Likewise, A study conducted among health professionals during pandemic flu in India revealed that health care professionals demonstrated lower anxiety levels. ${ }^{27}$

Compared to the reviewed literatures from different parts of the world, our findings are consistent in general with the study conducted in Singapore revealed that $14.5 \%$ participants screened positive for anxiety and anxiety was higher among non- medical health workers than medical personnel. This could be due to increase mental preparedness and infection control measures by the medical health workers. ${ }^{16}$ In addition, a multi centre study conducted in Singapore and India revealed that $(8.7 \%)$ of health workers experienced moderate to extremely-severe level of anxiety. ${ }^{11}$. However, our findings are lower than the study finding of Lai et al. which revealed that $22.6 \%$ of medical staff had mild to moderate anxiety and $2.9 \%$ had severe anxiety with regards to factors like several working in the isolation ward, worrying about being infected, shortage of the protective equipment, the epidemic would never be controlled, frustrated with unsatisfactory results and feeling lonely with being isolated from loved.$^{28}$ Similarly, studied conducted in china revealed that less than half of the health care members reported signs of anxiety especially women nurses while treating the patients. ${ }^{28,29}$ Further, study done by Badahdah and colleague revealed that $74.1 \%$ of health care workers experienced minimal to mild anxiety $(35.5 \%$ and $38.7 \%$, respectively) whereas, rest $(25.9 \%)$ reported moderate to severe anxiety $\left(17.7 \%\right.$ and $8.3 \%$, respectively)..$^{30}$ The variations in findings might be due to use of different measurement scales and cut-off points adopted by the studies. Furthermore, the variations in degree of stress and anxiety score might be due to the fact that our country still is in the early stage of corona outbreak.

The present study has some limitations. Firstly, stress and anxiety was assessed among the nurses through web based survey which might not include those nurses who were unable to respond due to various reasons. Secondly, it was limited in the scope since it contributed only the nurses from specific setting. Thirdly, this was a cross-sectional study which could not explore the casual link between the stress and anxiety and its associated factors and lacks the longitudinal follow- up. Because of the increasingly strenuous situation, the symptoms may vary in daily basis. Thus long term duration is worth the further investigation. Future study is recommended to find out factors associated with stress and anxiety learning using a higher statistical analysis for a better understanding of factors that influence stress and anxiety among the nurses. As our survey covers the limited area of assessment more items can be added in the instrument to get the effective results in this global pandemic period. The long-term mental health impact of COVID-19 might take weeks or months to become fully apparent, and managing this impact requires concerted effort from the health care system. Hence, there is a need to develop mental health interventions which are time-limited, culturally sensitive in order to improve the mental health among the nurses.

\section{CONCLUSION}

In summary, considerable proportion of nurses working in various wards of showed symptoms of stress and anxiety during COVID-19 pandemic. Therefore, the concerned authority has to conduct psychological interventions and support like stress relieving programs, motivational program to enhance better working environment among nurses for standardization in patient care.

\section{ACKNOWLEDGEMENT}

Authors of this study would like to express deep sense of gratitude towards all the participants of the study, without their cooperation this study would not have been successful.

\section{CONFLICT OF INTEREST: None}

\section{FINANCIAL DISCLOSURE: None}

5. Shanafelt T, Ripp J, Trockel M. Understanding and addressing sources of anxiety among health care professionals during the COVID-19 pandemic. JAMA. 2020;323(21):2133-4. [DOI]

6. Ford S, Ford S. Global nursing body issues warning on nurse mental health during Covid-19 crisis | Nursing Times [Internet]. Nursing Times. 2020 [cited 28 May 2020]. [LINK]

7. Tandon R. The COVID-19 pandemic, personal reflections on editorial responsibility. Asian J Psychiatr. 2020;50:102100. [DOI]

8. Chen KY, Yang CM , Lien CH, et al. Burnout, job satisfaction, and medical malpractice among physicians. Int J Med Sci. 2013;10(11):1471-8. [DOI]

4. Kang L, Li Y, Hu S, Chen M, Yang C, Yang BX, et al. The mental health of medical workers in Wuhan, China dealing with the 2019 novel coronavirus. The Lancet Psychiatry. 2020;7(3):e14. [DOI] 
9. Mo $Y$, Deng $L$, Zhang L, Lang $Q$, Liao $C$, Wang N, et al. Work stress among Chinese nurses to support Wuhan in fighting against COVID-19 epidemic. J Nurs Manag. 2020 ;28(5):1002-1009. [DOI]

10. Huang JZ, Han MF, Luo TD, Ren AK, Zhou XP.Mental health survey of 230 medical staff in a tertiary infectious disease hospital for COVID-19.2020;38(3):192-195. [DOI]

11. Chew NW, Lee GK, Tan BY, Jing M, Goh Y, Ngiam NJ, et al. A multinational, multicentre study on the psychological outcomes and associated physical symptoms amongst healthcare workers during COVID-19 outbreak. Brain, Behav Immun. 2020.88:559-565. [DOI]

12. Kisely S, Warren N, McMahon L, Dalais C, Henry I, Siskind D. Occurrence, prevention, and management of the psychological effects of emerging virus outbreaks on healthcare workers: rapid review and meta-analysis. BMJ. 2020;369: m1642. [DOI]

13. Cohen S, Kamarck T, Mermelstein R. Perceived stress scale. Measuring stress: A guide for health and social scientists. 1994;10:12. [LINK]

14. Zung WW. A rating instrument for anxiety disorders. Psychosomatics. 1971;12(6):371-9. [DOI]

15. Shen X, Zou X, Zhong X, Yan J, Li L. Psychological stress of ICU nurses in the time of COVID-19. Crit Care. 2020;24(1):200. [DOI]

16. Tan BY, Chew NW, Lee GK, Jing M, Goh Y, Yeo LL, et al. Psychological impact of the COVID-19 pandemic on health care workers in Singapore. Ann Intern Med. 2020;173(4):317-30. [DOI]

17. Bettinsoli ML, Di Riso D, Napier JL, Moretti L, Bettinsoli P, Delmedico M, Piazzolla A, Moretti B. Psychological Impact and Contextual Factors Associated With Physical and Mental Health Conditions of Italian Healthcare Professionals During the Covid-19 Disease Outbreak [LINK]

18. Mukhtar S. Mental health and emotional impact of COVID-19: applying health belief model for medical staff to general public of Pakistan. Brain Behav Immn. $2020 ; 87: 28-29$. [DOI]

19. Roy D, Tripathy S, Kar SK, Sharma N, Verma SK, Kaushal V. Study of knowledge, attitude, anxiety \& perceived mental healthcare need in Indian population during COVID-19 pandemic. Asian J Psychiatry. 2020;51:102083. [DOI]

20. Xiang YT, Yang Y, Li W, Zhang L, Zhang Q, Cheung T. Timely mental health care for the 2019 novel coronavirus outbreak is urgently needed. Lancet
Psychiatry. 2020;7(3):228-229. [DOI]

21. Maunder R, Hunter J, Vincent L, Bennett J, Peladeau N, Leszcz M et al. The immediate psychological and occupational impact of the 2003 SARS outbreak in a teaching hospital. CMAJ. 2003;168(10):1245-1251. [PMID]

22. Tam CWC, Pang EPF, Lam LCW, Chiu HFK. Severe acute respiratory syndrome (SARS) in Hong Kong in 2003: stress and psychological impact among frontline healthcare workers. Psychol Med. 2004;34(7):1197-204. [DOI]

23. Shen X, Zou X, Zhong X, Yan J, Li L. Psychological stress of ICU nurses in the time of COVID-19. Crit Care. 2020; 24(1):200. [DOI]

24. Feng $M C$, Wu $H C$, Lin $H T$, Lei $L$, Chao $C L$, $L u C M$, et al. Exploring the Stress, Psychological Distress, and Stress-relief Strategies of Taiwan Nursing Staffs Facing the Global Outbreak of COVID-19. Hu Li Za Zhi. 2020;67(3):64-74. [DOI]

25. Liu CY, Yang YZ, Zhang XM, Xu X, Dou QL, Zhang WW, et al. The prevalence and influencing factors in anxiety in medical workers fighting COVID-19 in China: A cross-sectional survey. Epidemiol Infect. 2020;148:e98. [DOI]

26. Pappa S, Ntella V, Giannakas T, Giannakoulis VG, Papoutsi E, Katsaounou $P$. Prevalence of depression, anxiety, and insomnia among healthcare workers during the COVID-19 pandemic: A systematic review and meta-analysis. Brain Behav Immun. 2020 Aug;88:901-907. [DOI]

27. Mishra P, Bhadauria US, Dasar PL, Kumar S, Lalani A, Sarkar P, et al. Knowledge, attitude and anxiety towards pandemic flu a potential bio weapon among health professionals in Indore City. Przegl Eepidemiol. 2016;70(1):41-5, 125-7. [LINK]

28. Lai J, Ma S, Wang Y, Cai Z, Hu J, Wei N, et al. Factors associated with mental health outcomes among health care workers exposed to coronavirus disease 2019. JAMA Netw Open. 2020;3(3):e203976. [DOI]

29. Mo $Y$, Deng $L$, Zhang $L$, Lang $Q$, Liao $C$, Wang $N$, et al. Work stress among Chinese nurses to support Wuhan in fighting against COVID-19 epidemic. J Nurs Manag. 2020 Jul;28(5):1002-1009. [DOI]

30. Badahdah A, Khamis F, Al Mahyijari N, Al Balushi M, Al Hatmi H, Al Salmi I, et al. The mental health of health care workers in Oman during the COVID-19 pandemic. International Journal of Social Psychiatry. $2020 \mathrm{Ju}$ 8:0020764020939596. [DOI] 